\title{
Views and Perceptions of Teachers and Adolescents on Adolescent's Pregnancy in School in Kavango Region, Namibia
}

\author{
Article by Taimi Amakali Nauiseb ${ }^{1}$, Joan M. Kloppers ${ }^{2}$, Honore K. Mitonga ${ }^{3}$ \\ 1,2 School of Nursing, University of Namibia, \\ ${ }^{3}$ School of Public Health, University of Namibia \\ E-mail: tnauiseb@unam.na ${ }^{1}$
}

\begin{abstract}
The objective of this study was to determine the views and perceptions of teachers and adolescent's on adolescent's pregnancy in school in Kavango Region, Namibia.

A cross-sectional analytical study was conducted using mixed methods - quantitative approaches among 350 school learners (grade 6 to grade 12) and 150 school dropout adolescents (aged 12 to 19 years). For the qualitative approaches 15 school learners and 25 teachers went through an in-depth interview. In total a sample of 540 was utilized.

The stratified random sampling techniques were used in the selections of the circuit and the schools. Structured questionnaires were used in face-to-face interviews, and in depth interviews were conducted among the key informants (teachers).

Themes and subthemes were identified and discussed: Challenges for learners in grasping or understanding the concept on reproductive health towards; Poverty - early marriages, bribe from men. Identified cultural barriers on reduction of the prevalence of adolescent pregnancy, towards; Culture - uncomfortable and shy to talk about sex.

The study found that the following aspects/factors: lack of parental supervision; poverty; lack of knowledge and communication skills to talk to their children regarding sex \& contraceptives; parental irresponsibility; lack of sex education; were associated with adolescent pregnancy in Kavango region.
\end{abstract}

Keywords: Adolescents, Teachers, Reproductive health, Sexual health.

\section{Introduction}

Teenage pregnancies give an impression of being unwanted because they are never planned. According to (USAID, 2011) 91\% of teenage pregnancies in the Kavango region in Namibia were unwanted. The unplanned and unwanted pregnancies among teenage girls are often terminated by unsafe abortions, which may have a long-term negative effect on their social and emotional being. The Demographic Health Survey as reported in Ministry of health \& social service, (MOHSS) 2013 and USAID 2011study revealed that the teenage pregnancy rate in the Kavango Region was double the national average, standing at $34 \%$ among the 15 19 year old. The national average teenage pregnancy rate was $15 \%$ and $15.4 \%$ respectively; and three times the rates in some of the neighboring regions, such as Ohangwena, Omusati, and Oshana.

In Namibia, 2015 the prevalence of adolescent pregnancy was $31.3 \%$; and as stated by Lillian \& Mumbango , 2015, adolescent pregnancy was influenced by generation, region, highest educational level, socio-economic status and cultural factors. Therefore, intervention programs and policy initiatives should focus on youth, regions, everyone regardless of the socio-economic or culture.

Although different regions of Namibia are affected, Kavango region in Northern Namibia is mostly affected by the problem of teenage pregnancy. According to a USAID report (USAID, 2011), the region has the highest rate of 34\% teenage pregnancy among 15 to 19 year olds.

With the commemoration of the World Population Day, the United Nations Population Fund (UNFPA,2013), released these statistics, which is celebrated on the 11 July every year. 
This year the theme was "Investing in Teenage Girls "When the statistics were compiled, there were 245431 adolescent girls population in Namibia aged between 15 and 19. 46000 adolescent fell pregnant, $66 \%$ of the population between 15 and 19, 39\% below the age of 15 .

As previously stated, the pregnancy rates are high in some regions, with $20 \%$ of teenagers in some rural areas becoming mothers earlier than their counterparts in urban areas. One of the reasons being is that rural teenage girls only have primary-level education, while girls in urban areas are better educated. Apart from the academic factor, the report also said some girls do not know how to avoid falling pregnant, while others feel shy or are ashamed to access contraceptives (Kangootui, 2016; UNFPA, 2013).

The USAID report (USAID, 2011) on teenage pregnancy in Kavango region indicates that lack of access to family planning as a result of the traditional orientation of family planning in favor of older and married women by health care providers is partly responsible for teenage pregnancy in the region. Furthermore, the report indicated that while $98 \%$ of young people in Kavango were informed about contraceptives, but only $8.7 \%$ of them use it. Condom use in the Kavango Region was very low at $36 \%$.

In Namibia the prevalence of adolescent pregnancy was $31.3 \%$; and as stated by Lillian \& Mumbango, 2015, adolescent pregnancy was influenced by generation, region, highest educational level, socio-economic status and cultural factors. Intervention programs and policy initiatives should focus on youth, regions, everyone regardless of the socio-economic or culture.

Adolescent pregnancy was considered a private matter that only involved the pregnant adolescent and the immediate family members. This issue has now however become a public concern. An increasing awareness of social and economic consequences of adolescent pregnancy has led to a consensus among researchers and policy makers and the general public at large that adolescent pregnancy and childbearing is a serious social problem. It is linked to concerns such as the spread of HIV/ AIDS, non-marital births, sexual abuse and neglect, abortions, infant and maternal mortality, high rate of unemployment, school failure and dropouts, and loss of self-esteem and limited future career opportunities (Lillian \& Mumbango 2015).

This article was extracted from the authors study "a model for reproductive health and pregnancy preventing strategies among adolescents in schools in Kavango region, Namibia" and thus cover the results related to the study to determine views and perception of teachers and adolescent on adolescent's pregnancy in Kavango, Region, Namibia.

\section{Objectives}

The objective of this study was to determine views and perception of teachers and adolescents on adolescent's pregnancy in Kavango, Region, Namibia.

\section{Limitation of the study}

The study focused only on public schools in Kavango region. Therefore, the outcomes of the study can only be recommended developing a model for adolescents within the public schools in Kavango regions. Consequently, the findings of the study need to be adjusted to the rest of the other schools in other regions in the country in order to be generalized. So, yes generalization of findings to the whole Namibian country will be applicable and will be done. Generalization of the study to Africa, the answer will be no because the model need to be adapted according to the countries culture and needs which need to be country specific. The model needs to be benchmark and due to constraints in time and resources implementation and evaluation of the model will not be completed now at the specific point in time.

\section{Delimitation of the study}

The study was carried out solely in Kavango region and not in any other regions of the country. The model needs to be benchmark and due to constraints in time and resources 
implementation and evaluation of the model will not be completed now at the specific point in time.

\section{Methods}

\section{Study design}

A cross-sectional analytical study was conducted using mixed methods - quantitative approaches among 350 school learners (grade 6 to grade 12) and 150 school dropout adolescents (aged 12 to 19 years). For the qualitative approaches 15 school learners and 25 teachers went through an in-depth interview. In total a sample of 540 was utilized.

The stratified random sampling techniques were used in the selections of the circuit and the schools. Structured questionnaires were used in face-to-face interviews, and in depth interviews were conducted among the key informants (teachers).

\section{Study population}

The study population groups were in three fold, the school learners in primary or secondary school, the teachers at different schools and the adolescent's in the community who had dropped out of school.

\section{Target population}

The first target population were the school learners falling within the age group of between 12- 19 years, in public primary and as well secondary schools in Kavango region. The second target population were teachers at different schools teaching Life Science, Life Skills, Biology or Natural Science. The third target populations were the adolescent's in the communities who had dropped out and or never went to school and falls within the age group of between 12- 19 years.

\section{Sample size}

A sample size of 500 adolescents was determined using Epi-info version 7 considering at least $95 \%$ significance level for the quantitative approaches. For the qualitative approaches 15 school learners and 25 teachers went through an in-depth interview. In total a sample of 540 was utilized.

\section{Data collection: preparing the field}

For both the schools and the community: Prior telephonic arrangements were done with the school principals and councilors regarding the purposes of the visit, date and time for the visits to Kavango Region and to the specific schools.

\section{Data collection procedure at schools}

The researcher reported at the principal office whereby the researcher submitted all written proof of letters for permission as obtained from the different institutions.

The principal accompanied the researcher to the Laboratory classroom or Life Skills class where the data collection took place. At some schools, the teacher responsible for Life Science, Life Skills, Natural Science or Biology accompanied the researcher to the Laboratory classroom or to the Life Skills class where the data collection took place. At some instances the learners waited at the mentioned classrooms and at other schools learners were called for the data collection once the researcher turned up.

The researcher was provided in advance with the class list of the specific grades, and carried out simple random selection. At the Primary schools: all learners from the different grades 6-7 came to the one central classroom, which was the Life Skills class's room. At the Secondary schools: all learners from the different grades 8-12 came to the one central classroom, which was the Life Skills, Biology or the laboratory classroom.

After explaining the aims of the study and obtaining permission from the learners and teachers. Individual in-depth face-to-face interview was carried out with the teachers offering 
Texila International Journal of Public Health

Volume 5, Issue 2, Jun 2017

at school the abovementioned subjects and the selected learners. The teacher's in-depth interview pointed out their challenges, experiences and shortcomings with the implementation of the curriculum. The data collected by the main researcher focused on reproductive issues, whether it is included and discussed comprehensively or partly in the abovementioned subjects.

\section{Data analysis}

Subthemes were identified and discussed which is as follows:

\section{Results from in depth interview with teachers and principal}

1. What's your sex?

$40 \%(10)$ of the respondents were males and $60 \%(15)$ were females.

2. What's your age?

Mean age of the responses was 36 years and the age range was between 23-49 years.

3. What are your highest qualifications?

$60 \%(15)$ of the teachers in possession of a diploma; followed by $32 \%(8)$ with a degree; next in line those teachers with a certificate with $8 \%$ (2), those with a Master's Degree 4\% (1) and $0 \%$ with doctoral degree.

4. Which grade(s) are you currently teaching?

The range of the grades been taught, grade $4-12$. Most of teachers teach more than one grade.

5. What subjects are you teaching?

$36 \%$ (9) of the respondents teach Life Skills; similarly $28 \%$ (7) teach both Life Science and a $28 \%$ (7) Natural Science respectively; 24\% (6) teach Biology and $8 \%$ (2) teach any other subjects.

6. How long have you been teaching this subject?

Mean period of teaching was (7) years, which makes out $28 \%$. Minimum years of teaching2 years ( $8 \%$ ) and maximum years of teaching was 18 years $(72 \%)$.

7. Are you comfortable in teaching this subject?

$96 \%$ (24) of the respondents indicated yes and 4\% (1) indicated no.

8. Do your school curriculums include the following topics: Respondents were having option to circle 3 responses?

96\% (24) indicated that HIV/AIDS is included in their curriculum and as well; 92\% (23) pointed out Sexually transmitted diseases; similarly $84 \%$ (21) indicated Contraceptives and as well $84 \%$ (21) Pregnancy respectively; followed by $=52 \%$ (13) for Sex education; and 20\% (5) for others.

9. How often do you teach these abovementioned topics?

$40 \%$ (10) of the teachers indicated once in a month; $36 \%(9)$ indicated as weekly;

$8 \%$ (2) indicated Three times in a week; and $2 \%$ (1) twice in a month and $0 \%$ as Twice in the week respectively.

10. How will you describe the involvement/participation of your learners during your classes?

Teachers responded that $68 \%$ (17) were fully participating; $28 \%$ (7) partly participating; and 2\% (1) were not participating at all.

11. How will you explain the attitudes of the learners in your class as you teach these abovementioned topics?

$68 \%$ (17) of the learners were having an Opened attitude; 32\% (8) were Shy and; $0 \%$ were Ashamed. 
12. Did you attend workshop/training in the abovementioned topics?

$52 \%$ (13) of the respondents stated NO that they have not attended workshop/trainings in this regard while $40 \%$ (10) stated Yes, they did attend workshop/trainings.

13. How often do you attend workshop/training in the abovementioned topics?

$48 \%$ (12) pointed out once a year; $40 \%$ (10) pointed out None/not yet invited; $2 \%$ (1) indicated once in six month and $0 \%$ indicated for Quarterly and as well every second year.

14. Are you involved in the curriculum development of the abovementioned topics?

$80 \%$ (20) of the respondents indicated Nowhile, 16\% (4) indicated yes for being involved in the curriculum development.

15. Is there a platform where you can share your input/suggestions regarding the curriculum of the abovementioned topics?

$48 \%$ (12) of the respondents indicated No while 44\% (11) indicated yes.

16. In your opinion do the curriculums address in full the abovementioned topics?

$76 \%$ (19) of the respondents indicated yes while, $24 \%$ (6) indicated No.

17. What are the main factors of high adolescent pregnancy rate in Rundu?

Respondents were having option to circle 3 responses. 80\% (20) Lack of parental supervision; 76\% (19) Poverty; 64\% (16) Lack of knowledge and communication skills to talk to their children regarding sex \& contraceptives; $44 \%$ (11) Parental irresponsibility; $28 \%$ (7) Lack of sex education; 16\% (4) Very low contraceptive utilization and 0\% Domestic violence.

18. What are some of the effective measures in preventing adolescent pregnancy?

64\% (16) Talks in schools; 56\% (14) Reproductive Health education and 56\% (14) Family planning education respectively; similarly Talks at community events and Educational films on Health \& Family planning with $52 \%$ (13) and Talks on radio $24 \%$ (6).

Main themes and subthemes were identified which is illustrated in Table 1.

Table 1. Views and perceptions of teachers on adolescent pregnancy in Kavango region.

\begin{tabular}{|c|c|}
\hline Main themes & Sub - Themes \\
\hline $\begin{array}{l}\text { 1. Challenges for learners in } \\
\text { grasping and understanding } \\
\text { the concept on reproductive } \\
\text { health. }\end{array}$ & $\begin{array}{l}\text { - Poverty - early marriages, bribe from men. } \\
\text { - Culture - uncomfortable and shy to talk about } \\
\text { - } \text { Lex. } \\
\text { engage in sex. } \\
\text { - Learn something at school just for examination } \\
\text { purposes. } \\
\text { - Different reactions of learners: } \\
\text { - Shyness } \\
\text { - Loses concentration } \\
\text { - Lack of interest } \\
\text { - Lack of participation } \\
\text { - Peer pressure } \\
\text { - Lack of family planning. } \\
\text { - Lack of health education. }\end{array}$ \\
\hline $\begin{array}{l}\text { 2. Identified cultural barriers } \\
\text { on reduction of the } \\
\text { prevalence of adolescent } \\
\text { pregnancy. }\end{array}$ & $\begin{array}{l}\text { - Early marriages } \\
\text { - Give birth while young to test fertility. } \\
\text { - Sex matters taboo. } \\
\text { - Religious beliefs do not allow girls to talk about } \\
\text { sex contraceptives. } \\
\text { - In some cultures contraceptives are completely } \\
\text { banned. }\end{array}$ \\
\hline
\end{tabular}




\begin{tabular}{|c|c|}
\hline & $\begin{array}{l}\text { - Parents should have very strict rules at home to } \\
\text { prevent early marriages. } \\
\text { - What is taught at school might be against their } \\
\text { religion. } \\
\text { - Must have an open relationship with parents. } \\
\text { - They say we must produce more to replace fore } \\
\text { parents. } \\
\text { - Producing a lot of children is an asset. }\end{array}$ \\
\hline $\begin{array}{l}\text { 3. Possible mechanisms, which } \\
\text { could be put in place at local } \\
\text { levels to prevent } \\
\text { pregnancies. }\end{array}$ & 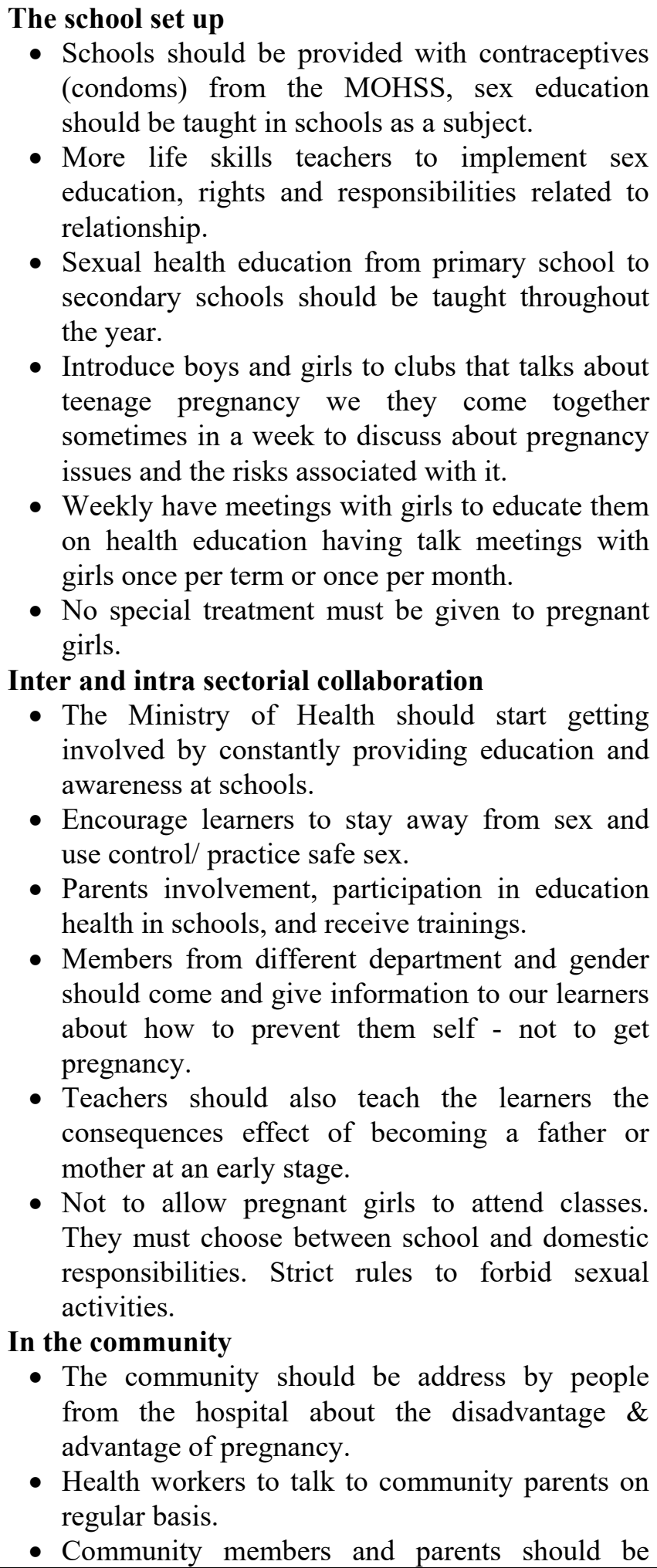 \\
\hline
\end{tabular}




\begin{tabular}{|l|l|}
\hline encouraged to talk freely about teenage \\
pregnancy, health, reproductive and sex \\
education. \\
Positive parenting and reproductive health \\
- Parents should also be educated on how to help \\
their children, education should start at home. \\
- Strong parental supervision and control over the \\
socialization of their children, and the \\
overwhelming love for new technological \\
appliances -Parents must continuously monitor \\
and supervise what their girl-child do thoroughly \\
and create the atmosphere of trust between \\
mother, father and daughter. \\
- Establish community taskforce against \\
adolescent pregnancy. \\
- NAPPA should educate the community on the \\
danger of early marriage and exchange of sex for \\
economic gains and poverty. \\
- Organization must reach people in the \\
community to do awareness about it. \\
- Severe punishment must be given to the males \\
that impregnate adolescents. \\
- Health specialists to gather and sensitize \\
community about these issues regularly. \\
- Girls who have children must be encouraged to \\
get a job and take care of their children for a \\
healthy upbringing. \\
- Supervision and strict rules with punishment \\
measures. \\
\hline a
\end{tabular}

Main themes and subthemes were discussed which is as follows:

\section{Discussion of themes and sub themes}

1. Challenges for learners in grasping/ understanding the concept on reproductive health.

\section{Subtheme 1}

\section{- Poverty - early marriages, bribe from men.}

Poverty is one of the main reasons for early child marriages. Where poverty is acute, giving a daughter in marriage allows parents to reduce family expenses by ensuring they have one less person to feed, clothe and educate.

Glinski, Allison, Sexton, and Meyers, (2015) stated that more than $50 \%$ of girls from the poor families in the developing world, married as children. Girls from poor families are three times higher to get married before the age of 18 as girls from wealthier families, UNFPA (2013).

\section{- Culture - uncomfortable and shy to talk about sex.}

According to Archual, (2014) culture have a huge influence on people not to talk about sex Namibia is no exceptional. Sex happens everywhere, all the time, all around the world; and in many other parts of the world, it can also be freely and openly discussed without fear of social taboo. In places like the Netherlands, Germany, and France, sex is considered to be, both in conversations at home and in schools, a natural part of a healthy relationship. It is regarded as an act of love and intimacy-something that can definitely be talked about. In cultures where individuals can talk openly discursively, about their sexual desires, it's easier to cut through the murkiness we've created around consent and get to that point of common understanding 
Archual, (2014).One danger involved with a culture that shames sex is disrespect among peers. As pointed out by Oliver, (2016) regardless of your personal sexual choices (waiting for marriage, not waiting, partaking in group sex, etc.), orientation, and preferences, it's important to respect other people's sexuality.

In Malawi, Limaye, (2012) says that parents are shy to talk about sex while

There is a need to increase efficacy to talk about sex and protective sexual

Strategies... cultural systems and media as sources of information on

HIV/AIDS can lead to troubles (about sex). ... Elders also felt

Uncomfortable talking about sex.

\section{- Not patient to wait for the right time.}

As illustrated by Schwenkler (2016), today, let's get a few things straight: (USAID, 2011). When the time is right, your person will come into your life (please don't kick me in the face, K thanks?), and (MoHSS, 2013). When your person does come into your life, (s) he will not save you, complete you, nor make you whole.

\section{- Learn something at school just for examination purposes.}

Students say that they only learn hard to pass the examination.

Tailor, (2016) mentioned that students are working harder than ever to pass tests but school allow no for true learning in the Socratic tradition. ... In point of fact, it is more than just dream. My real classroom ... If schools are to fulfill their purpose, they cannot afford to neglect this philosophical dimension of learning.

\section{- Different reactions of learners:}

Students can show different reactions, they are all the time under peer pressure as well of suffering under family problems. Some can go to the extend to commit crimes as well as suicide.

- Shyness

- Loses concentration

- Lack of interest

- Lack of participation

- Peer pressure

- Lack of family planning

According to UNFPA, (2013) access to safe, voluntary family planning is a human right. Family planning is central to gender equality and women's empowerment, and it is a key factor in reducing poverty. Yet some 225 million women who want to avoid pregnancy are not using safe and effective family planning methods, for reasons ranging from lack of access to information or services to lack of support from their partners or communities. Most of these women with an unmet need for contraceptives live in 69 of the poorest countries on earth.

Alexandrescu, Tuchendria, conducted a baseline examination (1999), in which data were collected from 279 students who attended five high schools and six post high schools from the Moldavia cities, Iassy, Piatra-Neamt and Bîrlad. Students were asked to complete a selfadministered questionnaire, and a $97.5 \%$ response rate for the whole survey was achieved. Differences between answers were tested using chi-square test from $2 \times 2$ table and median test, average. A P-value $<0.05$ was considered to be significant. The study established that knowledge; attitudes and practice vary by age (adolescents $(<$ or $=19 \mathrm{y})$ vs. young people $(>19 y)$ ) and education (high school vs. post high school) in some regards. At the aggregate level, regarding knowledge, a statistically significant difference was found between adolescents and young people; but no statistically significant difference was found between high school and post high school students. Apart from lack of basic knowledge the study confirmed that the survey participants hold many false beliefs regarding contraceptives. People who were sexually active were no better informed than the rest of survey participants, 
but they had a significantly higher percentage of positive attitudes regarding effectiveness of pills and withdrawal.

Table 2. Prevalence of adolescent pregnancy in schools per term in Kavango region

\begin{tabular}{|l|l|}
\hline Total pregnant adolescents per term & Percentages \\
\hline $2-3$ cases per term & $0.4 \%-0.6 \%$ \\
\hline $5-7$ cases per term & $1 \% .-1.4 \%$ \\
\hline $8-10$ cases per term & $1.6 \%-2 \%$ \\
\hline $11-19$ cases per term & $2.2 \%-3.8 \%$ \\
\hline
\end{tabular}

The pregnancy rates under adolescent in schools are increasing in Namibia. The abovementioned cases are those cases observed by the teachers and others might go unnoticed. Despite that we are having three school calendar terms; the above mentioned cases are examples of different cases which might be experience from one school term to another and do not necessary correspond to a specific school term.

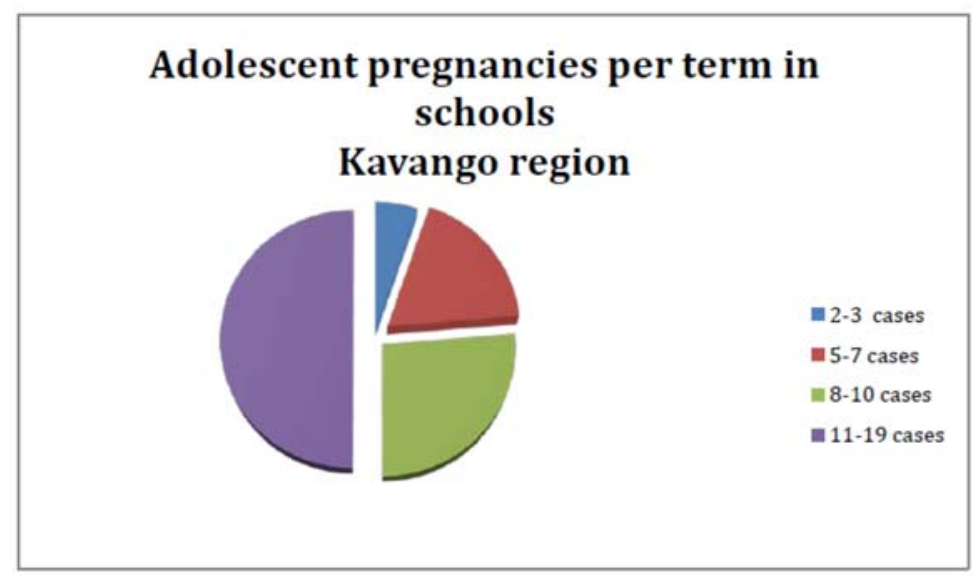

Figure 1. Prevalence of adolescent pregnancy in schools per term in Kavango region.

\section{Results from in depth interview with adolescents.}

\section{Section 1: Demographic information}

Age: Mean age of the participants was 16 years and the age range was between 12-19 years.

Sex: $40 \%(6)$ of the participants were males and $60 \%(9)$ were females.

Grade: The grades of the participants were as follow: 53.3\% (8) for Grade $11 ; 26.7 \%$ (4) for Grade 9 and 20\% (3) Grade 8.

Living: $46.7 \%$ (7) live with both parents, $20 \%$ (3) live in the Hostel, 13.3\% (2) live with their Father; 6.7\% (1) live both Mother and the Aunt, and as well with the Grandmother.

\section{Section 2: Knowledge and perceptions about adolescent health-care service}

1. Which health facility did you visit, clinic or hospital?

$80 \%$ (12) of the participants visited public health clinic and 6.7\% (1) visited the hospital, $6.7 \%$ (1) visited private doctors and $6.7 \%$ (1) private clinics respectively.

Most of the participants prefer visit the public health clinics. They are not so expensive as the private doctors and the private clinics. With the private doctors you need to make an appointment and must have a medical fund which most of the parents don't have? Participants can visit public health facilities any time with no appointment.

2. Which type of service did you go for?

Adolescents visited the health facility for the following services: Stomach pain; Headache and flu; Monthly check-up for tonsils; Eye test; Stitching of wounds; Asthma treatment; 
Texila International Journal of Public Health

Volume 5, Issue 2, Jun 2017

Sonar; Doctor's appointment; Check up on my eyes. Full body check-up and Family planning.

Activities of health services include identification of health problems, treatment of common ailments and injuries, referrals, growth monitoring, checkups, monitoring of outbreaks, vaccinations and referrals for appropriate treatment (Trainers of Trainers Manual on School Health, 2015).

3. Did you receive the health-care services that you went for?

$100 \%$ (15) of the participants pointed out that they received services accordingly.

4. Did you see informational materials for adolescents, including video or TV, in the waiting area?

$53.3 \%$ (8) stated yes while $46.7 \%$ (7) stated no there were no information about adolescents, but there were TV's available.

A lack of comprehensive education in school, home or youth centers may mean that adolescents do not acquire the necessary information (Trainers of Trainers Manual on School Health, 2015).

5. Did you see a display, which mentions that services will be provided to all adolescents without discrimination?

$33.3 \%$ (5) stated yes while $66.7 \%$ (10) stated no, but they were just some magazines of health, cars and insurance books. The MOHSS of Namibia have a program of Adolescent Friendly Services, which is incorporated, in 6 regions of Namibia to improve health services for the adolescents.

6. Did you feel welcome and safe at the health facility? $86.7 \%$ (13) pointed out yes while $6.7 \%$ (1) pointed out somehow and feel at home respectively.

Health workers receive training in adolescent Friendly health Services and receive

Marks. The clinic staff, administration staff and the cleaners need to be friendly towards the adolescents (Adolescent Friendly Health Services, 2012).

Table 3. Themes and Sub-themes

\begin{tabular}{|l|l|}
\hline Main Theme & Sub - Themes \\
\hline Physical Environment: & $\begin{array}{l}\text { - Environment: } \\
\text { Positive: Atmosphere is calm, Very clean } \\
\text { including smell. People come and make it dirty. } \\
\text { Clean toilet, smelled good with hand sanitizer } \\
\text { Negative: unhygienic smell and accommodates } \\
\text { many people leading to infection spread. Waiting } \\
\text { room was full of unhygienic people. }\end{array}$ \\
\hline Attitude: & $\begin{array}{l}\text { - Kind, helpful, respectful and happy } \\
\text { - Professional }\end{array}$ \\
\hline Health consequences of getting married & $\begin{array}{l}\text { - Abused by older partner } \\
\text { at a young age: }\end{array}$ \\
& $\begin{array}{l}\text { - No support } \\
\text { - Risk of getting infected }\end{array}$ \\
& - Prop out of school \\
& - Stress \\
& - Suicide \\
& - Financial problems \\
& - Death \\
& \\
\hline
\end{tabular}




\begin{tabular}{|l|l|}
\hline Contraception methods: & $\begin{array}{l}\text { - Condom } \\
\text { - Femidom }\end{array}$ \\
& $\begin{array}{l}\text { - Cervical cap } \\
\text { - Rhythm method } \\
\text { - Withdrawal and abstinence }\end{array}$ \\
\hline Waiting time: & $\begin{array}{l}\text { - } 5-30 \mathrm{~min}=8 \\
\text { - } 30-1 \text { hour }=5 \\
\text { - } 2-3 \text { hours }=2\end{array}$ \\
\hline Involvement of adolescents quality & $\begin{array}{l}\text { - Life science and biology teachers should } \\
\text { healthcare: }\end{array}$ \\
& teach learners to control themselves and the \\
& consequences \\
& - Should abstain \\
\hline
\end{tabular}

\section{Discussion of findings}

\section{Physical environment}

Some adolescents see the environment clean with a good smell while others are negative that the environment is dirty and does not smell hygienic.

\section{Attitude}

Most of the time the public complain about the health workers attitude. You read it in the newspapers on the radio. The adolescents have positive comments professional.

\section{Health consequences of getting married at a young age}

The adolescent know the consequences. They mentioned of getting married early.

The adolescents mentioned a long list like no support; Risk of getting infected; Drop out of school; premature death; Stress; Suicide; Financial problems; Death

According to the UNFPA (2013) delay of child bearing to experience maternal illness, miscarriage, stillbirth and neonatal death. Babies of teenage mothers are born with low birth weight and experience health development problems. Adolescent pregnancies can lead to financial burden to society.

\section{Contraception methods}

Contraceptives is called birth control, are usually used to prevent pregnancies. Many young people are sexually active and need to have more information regarding the different contraceptive methods that is available to them. Counseling dialogue between the adolescent and members of the Health-care team should be structured in making a decision that is informed, voluntary and appropriate to the adolescent' circumstances (Trainers of Trainers Manual on School Health, 2015).Adolescents may also be less likely to possess the motivation and skill to use a contraceptive method correctly. Even when adolescents have correct information about contraceptives, this will not guarantee that responsible sexual behavior will follow (Trainers of Trainers Manual on School Health, 2015).

\section{Waiting time}

The waiting time at health facilities is long due to staff shortage. Health workers are looking for greener pastures and financial freedom. The consequences of stigma and discrimination are wide- ranging. Some people are shunned by family, peers and the wider community while others face poor treatment in healthcare and education settings, erosion of their human rights and psychological damage (Trainers of Trainers Manual on School health Services, 2015). The respondents waiting time was as follows:

$2-3$ hours $=13.3 \%(2) ; 30$ minutes- 1 hour $=33.3 \%(5) ; 5-30$ minutes $=53.3 \%(8)$. 
Texila International Journal of Public Health

Volume 5, Issue 2, Jun 2017

\section{Involvement of adolescent's quality healthcare}

Most of the time adolescents are neglected, because health workers seen them as healthy people. In Namibia the Ministry of Health and Social Services have started with the Adolescent Friendly health services to accommodate the adolescent to receive excellent health services. Previous experiences with health- care workers or with health-care delivery sites are likely to influence the use of contraceptives services when the need arises (Trainers of Trainers Manual on School Health, 2015).

\section{Recommendations from teachers to prevent adolescent pregnancies}

Effective measures in preventing adolescent pregnancy should be enhanced and strengthen at schools.

- Sex education should be implemented in schools as a subject; schools must always put the topic of pregnancies on their agendas during parent meetings.

- The policy on family planning should make provision to allow girls older than 14 years to receive contraceptives for protection because most are already sexually active by age 13.

- Build self-confidence and respect, adolescent must realize their value and make right choice in their lives.

- By forcing them to leave school immediately once they are pregnant, learners to be more responsible and take care of themselves.

- The Ministry of Health should visit schools once in a while to teach young girls the importance of family planning/contraceptives.

- If the minds of people can be changed from how they lived in the past to what is happening now then we can be sure that our children's future will be different.

- Contraceptives have disadvantages so I would recommend schools and community teachings on sex education.

- Reduce alcohol and drugs abuse among parents and their children. School rules and policies such as those regarding the use of alcohol, tobacco and other substances can have a powerful effect on reinforcing health messages or practices in the school (Trainers of Trainers Manual on school Health).

- More teaching on reproductive health, parents must be taught to support their children.

- Educate young ones to abstain from sex and to make them aware of the risk involves.

\section{Conclusion}

The study found that the following aspects/factors: lack of parental supervision; poverty; lack of knowledge and communication skills to talk to their children regarding sex \& contraceptives; parental irresponsibility; lack of sex education; very low contraceptive utilization were associated with adolescent pregnancy in Kavango region.

\section{References}

[1]. Alexandrescu R, Tuchendria E. (1999). Teenagers, Young People and Family Planning: A Survey in Five Romanian High Schools. Doi: 10.1038/sj.ph.1900577 1999 Sep; 113(5): 219-26.

[2]. American College of Obstetricians and Gynecologist. (2007). Women's Health Care Physicians. Washington, DC.

[3]. Archual S. (2014). A Culture that Can't Talk Openly about Sex only Complicates the Question of Consent: So, let's talk... http://democraticvoices.com/2014/11/culture-corr.

[4]. Babington, L. M., Malone, L., \& Kelley, B. R. (2015). Perceived Social Support, Self Esteem, and Pregnancy Status among Dominican Adolescents. Applied Nursing Research: ANR, 28(2), 121-6. http://doi.org/10.1016/j.apnr.2014.08.001.

[5]. Brindis, C.D., Sattley, D., Mamo, L. (2005). From Theory to Action: Frameworks for Implementing Community-Wide Adolescent Pregnancy Prevention Strategies. San Francisco, CA: University of California, San Francisco, Bixby Center for Reproductive Health Research \& Policy, 
Department of Obstetrics, Gynecology \& Reproductive Sciences, and the Institute for Health Policy Studies. http://crhrp.ucsf.edu

[6]. Clarke. K. E. N, Kraft. J.M, Wiener. JB, Hatfield-Timajchy. K, Kottke. M, les. J. M, Goedken. P, Kourtis. A. P, (2016). Factors Associated with Contraceptive use differ between Younger and Older African- American Female Adolescents.

[7]. Denno. D. M, Hoopes. A. J, Chandra-Mouli. V. (2015). Effective Strategies to Provide Adolescent Sexual and Reproductive Health Services and to Increase Demand and Community Support. Health. Volume, January 2015, Pages S22-S41.International Conference on Population and Development.

[8]. Department of Reproductive Health and Research World Health Organization. (2011).Adolescent Pregnancy. Avenue Appia 20, CH-1211 Geneva 27, Switzerland E-mail: reproductivehealth@who.int. [9]. Fathalla. M. M. F \& Fathalla. M.F (2008.) Sexual and Reproductive Health: Overview. Assiut University, Assiut, EgyptsEt?

[10]. Glinski, Allison M., Magnolia Sexton, and Lis Meyers. (2015). Washington, DC: The Child, Early, and Forced Marriage Resource Guide Task Order, Banyan Global.

[11]. Godding J. (2008). Emergency Contraception. Emerg Nurse 16 (4), 22-24. 72008.

[12]. Gottschalk, L. B., \& Ortayli, N. (2014). Interventions to Improve Adolescents' Contraceptive Behaviors in Low- and Middle-income Countries: a Review of the Evidence Base. Contraception, 90(3), 211-25. http://doi.org/10.1016/j.contraception.2014.04.017

[13]. Johnson, K. M., Dodge, L. E., Hacker, M. R., \& Ricciotti, H. A. (2015). Perspectives on Family Planning Services among Adolescents at a Boston Community Health Center.Journal of Pediatric and Adolescent Gynecology, 28(2), 84-90. http://doi.org/10.1016/j.jpag.2014.05.010.

[14]. Kadivar, H., Thompson, L., Wegman, M., Chisholm, T., Khan, M., Eddleton, K., Shenkman, E. (2014). Adolescent Views on Comprehensive Health Risk Assessment and Counseling: Assessing Gender Differences.The Journal of Adolescent Health: Official Publication of the Society for Adolescent Medicine, 55(1), 24-32. http://doi.org/10.1016/j.jadohealth.2013.12.002

[15]. Liang. E. L. M. (2013). Adolescent Pregnancy: A Review of the Evidence. UNFPA New York.

[16]. Lillian P, Mumbango T. (2015). Statistical Modeling of Adolescent Pregnancy in Namibia. J Nurs Care 4: 262. Doi: Volume 4 Issue 4 10.4172/2167-1168.1000262.

[17]. Limaye, R.J., (2012). Talking About Sex in Malawi: Toward a Better Understanding of ... NCBI. https://www.ncbi.nlm.nih.gov > NCBI > Literature > PubMed Central (PMC).

[18]. Loaiza. E, Liang. M. (2013). Adolescent Pregnancy: A Review of the Evidence. UNFPA New York.

[19]. Macleod, C. and Tracey, T. (2001). Research on the Consequences of and Contributing Factors in Teenage Pregnancy. South African Journal of Psychology Grahams town: Rhodes University South Africa.

[20]. Mensah, E. (2002). Teenage Pregnancy and its Effect on a Girl Academic Progression in Kabakaba Educational Circuit in the Central Region. Ghana

[21]. Mburu, G., Ram, M., Oxenham, D., Haamujompa, C., Iorpenda, K., \& Ferguson, L. (2014). Responding to Adolescents living with HIV in Zambia: A Social-Ecological approach. Children and Youth Services Review, 45, 9-17. http://doi.org/10.1016/j.childyouth.2014.03.033.

[22]. Ministry of Education. (2012). Education Sector Policy on the Prevention and Management of Learner Pregnancy. Building a Learning Nation. Project Legal Assistance Centre.

[23]. Ministry of Education and Culture. (2008). School Policy on Learner Pregnancy in Namibia: Summary of Background Information: Gender Research \& Advocacy Project Legal Assistance Centre. [24]. Ministry of Health \& Social Services (MoHSS). (2013). Namibia Demographic Health Survey.

[25]. Ministry of Health \& Social Services (MoHSS). (2015). Trainers of Trainers Manual on School Health. School Health Division \& Ministry of Education.

[26]. Mushwana, L., Monareng, L., Richter, S., \& Muller, H. (2015). Factors influencing the Adolescent Pregnancy Rate in the Greater Giyani Municipality, Limpopo Province - South Africa. International Journal of Africa Nursing Sciences, 2, 10-18. http://doi.org/10.1016/j.ijans.2015.01.001.

[27]. Mogotsi, I. (1998). Formal Education and Pregnancy among Learners in Namibia. The Hague: Netherlands. 
Texila International Journal of Public Health

Volume 5, Issue 2, Jun 2017

[28]. Nomhle Kangootui. (2016). Pregnancy statistics in Namibia. Namibian Newspaper, p. 14 July 2016.

[29]. National Statistical Office United Nations Children's Fund. (2008). Teenage Pregnancy and Motherhood. Malawi.

[30]. Oliver, B. (2016). Get Uncomfortable: Let's Talk About Sex. Https://www.Theodysseyonline.com/getuncom

[31]. Olumide, A. O., Robinson, A. C., Levy, P. A., Mashimbye, L., Brahmbhatt, H., Lian, Q., Blum, R. W. (2014). Predictors of Substance use among Vulnerable Adolescents in five cities: findings from the wellbeing of Adolescents in Vulnerable Environments Study. The Journal of Adolescent Health: Official Publication of the Society for Adolescent Medicine, 55(6 Suppl), S39-47. http://doi.org/10.1016/j.jadohealth.2014.08.024.

[32]. Omar, K., Hasim, S., Muhammad, N. A., Jaffar, A., Hashim, S. M., \& Siraj, H. H. (2010). Adolescent Pregnancy Outcomes and Risk factors in Malaysia. http://doi.org/10.1016/j.ijgo.2010.06.023.

[33]. Richter \& Mlambo (2005). Perceptions of Rural Teenagers on Teenage Pregnancy. DOI: 10.4102/hsag.v10i2.195 Source: DOAJ

[34]. Schwenkler, T. (2016). Waiting on Love? Two Things You Probably Don't Know (But Should) Un-Lost http://www.theunlost.com/relationships/waiting

[35]. SIAPAC. (2010). Children and Young People in Namibia: Situational Analysis of Children and Adolescents in Namibia. Adolescent pregnancy in Upper Egypt.

[36]. Simon.K. (2013).Investigation of Teenage Pregnancy in Oshana Region.Namibia.

[37]. Tailor, J. (2016). Can School Today Teach Anything More than how to Pass Exams? - Aeon https://aeon.co/essays/can-school-today-teach-anything-more-than-how-to-pass-exams

[38]. Tesch, R. (1995). Qualitative research: Analysis Types and Software Tools. New York Falmer.

[39]. Thornberry, T. P., Krohn, M. D., Augustyn, M. B., Buchanan, M., \& Greenman, S. J. (2015). The Impact of Adolescent Risk Behavior on Partner Relationships. Advances in Life Course Research. http://doi.org/10.1016/j.alcr.2015.04.002

[40]. Tylee. A, Haller D.M, Graham. T, Churchill. R, Sanci. L.A. (2007). Adolescent Health: Youthfriendly primary-care services: How are we doing and what more needs to be done? Published Online March 27, 2007 DOI:10.1016/S0140- 6736 (07) 60371-7

[41]. UNFPA (2013). Marrying Too Young: End Child Marriage.

[42]. UNFPA (2013). United Nations Population Fund. Family Planning. http://www.unfpa.org/familyplanning\#sthash.e9YzAzWM.dpuf

[43]. UNICEF. (2012). Progress for Children: A Report Card on Adolescents, No 10, April 2012.

[44]. UNICEF, WHO, UNFPA, Global Fund, (2006). Multiple Indicator Cluster Survey (MICS).

[45]. United States Agency for International Development (USAID). (2011) Teenage Pregnancy in Kavango Region: Contributing Factors and Program Recommendation.

[46]. Walker, L. O., \& Avant, K. C. (2005). Strategies for Theory Construction in nursing (3rd ed). New Jersey: Pearson-Prentice Hall.

[47]. WHO (2014). Adolescent Pregnancy Fact Sheet, Department of Reproductive Health and Research, Geneva, Switzerland. 